marrow response would not support such a hypothesis. Antibody-mediated RCA is known to occur in chronic granulocytic leukaemia $^{6}$ but it is difficult to show in MDS because of poor or absent growth in vitro of erythroid progenitors, even in those patients with plentiful erythroblasts. ${ }^{7}$ Autoimmune phenomena, however, are common in patients with $\mathrm{MDS} .{ }^{8}$ Consequently those patients who have RCA and no excess of blasts may have a relatively good prognosis and should be considered for immunosuppressive treatment.

Four previous case reports of MDS and RCA have described a proliferative phase at the time of, or soon after, the onset of RCA. ${ }^{23}$ One of these cases also had an excess of blasts and all four had a relatively good prognosis. Two out of three treated with prednisolone showed at least a partial recovery of erythropoiesis. A transient response to prednisolone was also seen in a further case of chronic myelomonocytic leukaemia with RCA. ${ }^{5}$ This patient developed acute leukaemia within five months of diagnosis. Taken together with our six cases there seems to be a spectrum of disease in which autoimmune RCA may be superimposed on MDS, the latter showing a tendency to evolve to acute leukaemia over a very variable time course. The relevance of a proliferative element in these cases is unclear.
Thrombocytosis is a feature of the 5q-syndrome $^{9}$ (a subgroup within MDS), and many of these patients have a degree of erythroid hypoplasia. It is debatable, however, whether such patients should be considered in the same spectrum of disease as those described above.

1 Ammus SS, Yunis AA. Acquired pure red cell aplasia. Am J Hematol 1987;24:311-26.

2 Craig A, Geary CG, Love EM, Lin-Yin J. Red cell hypoplasia, thrombocytosis and leucocytosis: myelodysplastic and proliferative syndrome. J Clin Pathol 1988; 41:1168-70.

3 Cook MK. Red cell hypoplasia associated with myeloproliferative and myelodysplastic syndrome. J Clin Pathol 1988;42:890-1.

4 Boulton-Maggs PHB, Galloway MJ, Rhodes EGH. Pure red cell aplasia heralding chronic myelomonocytic leukaemia. Clin Lab Haematol 1989;11:61-5.

5 Lopez-Guillermo A, Cervantes F, Sacanella E, Florensa L, Rozman C. Pure red cell aplasia associated with chronic myelomonocytic leukaemia. Clin Lab Haematol 1989;11: 410-1.

6 Dessypris FN, McKee CL, Metantonakis C, Teliacos M, Krantz SB. Red cell aplasia and chronic granulocytic

7 Oscier DG, Worsley A, Darlow S, Figes A, Williams JD, Hamblin TJ. Correlation of bone marrow colony growth in the myelodysplastic syndromes with the FAB classification and the Bournemouth score. Leuk Res 1989;13:833-9.

8 Mufti GJ, Figes A, Hamblin TJ, Oscier DG, Copplestone JA. Immunological abnormalities in myelodysplastic syndromes. I. Serum immunoglobulins and autoantibodies. Br J Haematol 1986;63:143-7.

9 Kerkhofs H, Hagemeijer A, Leeksma CHW, et al. The 5qchromosome abnormality in haematological disorders. $\mathrm{Br}$ J Haematol 1982;52:365-81.
Servicio de Anatomía Patologica, Hospital Civil De Bilbao, 48013 Bilbao, Spain

J I López

J Alfaro

Departamento de Anatomía Patológica, Hospital 12 de

Octubre, Madrid,

Spain

C Ballestin

Correspondence to:

Dr J I López

Accepted for publication

21 November 1990

\author{
J I López, J Alfaro, C Ballestin
}

\begin{abstract}
Two cases of undifferentiated carcinomas of the major salivary glands were studied using immunohistochemical techniques. Results showed that this entity was a high grade malignant neoplasm arising from the excretory duct. Despite the undifferentiated appearance multiple immunophenotypes were evident in both cases.
\end{abstract}

Well defined, undifferentiated carcinomas of salivary glands are fairly uncommon high grade neoplasms. ${ }^{12}$ These tumours arise in major salivary glands, mainly in the parotid. ${ }^{2}$ Despite the fact that the light microscopic features are undifferentiated, ${ }^{1}$ electron microscopic studies have shown glandular or neuroendocrine features in some of them. ${ }^{2}$

In an attempt to detect differentiating features we recently studied two cases using immunohistochemistry.

\section{Case reports}

CASE 1

A 54 year old man presented with a tumour mass on the left side of his neck. The lesion had grown quickly over two months. Ipsilateral subdigastric lymph node metastases were also detected on physical examination. Lumpectomy and lymphadenectomy were performed. Macroscopically, the tumour measured $6 \mathrm{~cm}$ and showed multiple haemorrhagic foci. He died of metastatic disease three months later.

CASE 2

A 60 year old man presented with a large, left sided tumour mass on his neck. The tumour measured $12 \mathrm{~cm}$. Bilateral lymph node metastases on the lower neck were detected. Palliative surgical resection was performed. Macroscopically, there were multiple haemorrhagic foci with necrotic areas. Death followed rapidly. A post mortem examination was not performed.

In both cases metastatic disease from skin, lung, and gastrointestinal tract was ruled out as far as possible.

Both tumours were located in the parotid gland, and morphologically, fulfilled the light microscopic criteria of undifferentiated carcinomas of major salivary gland. Small or inter- 
Immunohistochemical panel and results

\begin{tabular}{llll}
\hline Antibody & Source & Case 1 & Case 2 \\
\hline AE1 & Hybritech & + & +++ \\
CAM 5·2 & Becton Dickinson & + & +++ \\
Keratin 13 & Progen & - & + (focal) \\
Keratin 903 & Enzo & - & +++ \\
Keratin 904 & Enzo & - & - \\
EMA (E29) & Dakopatts & + (focal) & + (focal) \\
CEA (PARLAM 4) & Eurodiagnostics & + (focal) & + (focal) \\
Gamma-enolase (MIG-N3) & Monosan & + (focal) & - \\
Chromogranin & Hybritech & - & - \\
Vimentin (V9) & Dakopatts & - & - \\
Actin (HHF-35) & Enzo & - & - \\
S-100 (polyclonal) & Dakopatts & - & - \\
\hline
\end{tabular}

AE1 (acidic keratins), CAM $5 \cdot 2$ (keratins 8, 18, 19), keratin 903 (keratins 1, 5, 10, 11), keratin 904 (keratin 1), EMA (epithelial membrane antigen), CEA (carcinoembryonic antigen), enolase (neurone specific gamma-enolase), actin (muscle specific actin).

mediate hyperchromatic cells with a high nuclear:cytoplasmic ratio and frequent mitoses were arranged in large lobes and strands. No evidence of differentiation was observed. Necrosis and bleeding were prominent features. An immunohistochemical study using several epithelial, mesenchymal, and neuroendocrine markers was performed (table).

\section{Discussion}

The immunohistochemical results expressed in the table basically agree with those of Hui et $a l .{ }^{2}$ Because of negative actin and S-100 protein immunostaining, an absence of myoepithelial cells could be assumed in our cases. Differentiation towards both glandular and neuroendocrine features occurred in case 1 , as was shown by positivity for AE1, CAM 5.2, CEA, and gamma-enolase. A complex expression of cytokeratins was evident in case 2; both glandular and non-keratinising squamous differentiation were seen.

The absence of a myoepithelial component in these cases has not been reported previously. According to Batsakis et al, ${ }^{3}$ this suggests a presumptive histogenetic origin from the excretory duct. On the other hand, multidirectional differentiation pathways occurring during oncogenesis may permit the simultaneous development of neuroendocrine and exocrine components. This fact, observed in case 1 , has also been recently reported in undifferentiated carcinoma of parotid gland ${ }^{4}$ as well as in other salivary gland neoplasms. ${ }^{5-7}$ Finally, expression of keratin 903 (cytokeratins $1,5,10$, and 11 , expressed by basal cells), as well as CAM $5 \cdot 2$ keratin (cytokeratins 8,18 , and 19) reflects the fact that multiple immunophenotypes occur in these carcinomas and adds further support to the notion of occult differentiating pathways.

1 Patey DH, Sobin LH. Histological typing of salivary gland tumors. In: International histological classification of tumors. In: International histological classification of

2 Hui KK, Luna MA, Batsakis JG, Ordonez NG, Weber R Undifferentiated carcinomas of the major salivary glands. Oral Surg 1990;69:76-83.

3 Batsakis JG, Regezi JA, Luna MA, El-Naggar A. Histogenesis of salivary gland neoplasms: A postulate with prognostic implications. J Laryngol Otol 1989;103:939-44.

4 Hayashi Y, Nagamine S, Yanagawa T. Small cell undifferentiated carcinoma of the minor salivary gland containing exocrine, neuroendocrine and squamous cells. Cancer 1987;60:1583-8.

5 Michaels L, Deguara J, Manuja SL, Papadaki L. Familial neuroendocrine carcinoma of salivary glands. $J$ Pathol 1990;161:355A.

6 Ito K, Kakudo K, Mori I, Horiuchi M, Osamura Y. Neuroendocrine differentiation in a case of acinic cell carcinoma of the parotid gland. Acta Pathol Jpn 1990;40:279-87.

7 Gnepp DR, Wick MR. Small cell carcinoma of the major salivary glands. An immunohistochemical study. Cancer 1990;66:185-92.

\title{
Morbidity survey of post mortem room staff
}

\author{
A J Hall, T C Aw, J M Harrington
}

\begin{abstract}
A retrospective study of post mortem staff who had taken leave due to sickness was carried out over a 12 month period throughout England and Wales. Eight hundred and nineteen post mortem room personnel (representing a $57 \%$ response) replied to individual postal questionnaires regarding their sick leave of two days or more, for the period June 1985 to June 1986. Complete responses were available for 751. Post mortem room technical staff reported more mean days sickness per person $(7 \cdot 8)$ than either pathologists $(1 \cdot 6)$ or a control group of coroners' officers (3.9). The annual inception rate (frequency by spells) was also higher among technicians than the other two groups. Technical staff had more infectious disease (0.73 mean days of
\end{abstract}

absence compared with pathologists $(0 \cdot 10)$ or coroners' officers $(0 \cdot 12))$ and more frequent absences due to cuts and lacerations.

Infection risks associated with health care work were at one time considered unavoidable. Despite epidemiological evidence that a demonstrable risk to health exists ${ }^{1-3}$ and the introduction of corresponding health and safety legislation, occupational morbidity in particular subgroups of health care workers is still evident. ${ }^{45}$ Certain categories of health care work are perceived to carry a greater inherent health risk, not only from contact with diseased subjects and blood and body fluids, but also from injury through the use of potentially dangerous equipment. One such occupation is post mortem work where both technical and medical staff are at risk. 